\title{
Article \\ Stakeholders' Risk Perceptions of Decarbonised Energy System: Insights into Patterns of Behaviour
}

\author{
Farid Karimi
}

check for updates

Citation: Karimi, F. Stakeholders' Risk Perceptions of Decarbonised Energy System: Insights into Patterns of Behaviour. Energies 2021, 14, 7205. https://doi.org/10.3390/en14217205

Academic Editor: Amy Brunsvold

Received: 2 September 2021

Accepted: 21 October 2021

Published: 2 November 2021

Publisher's Note: MDPI stays neutral with regard to jurisdictional claims in published maps and institutional affiliations.

Copyright: (C) 2021 by the author. Licensee MDPI, Basel, Switzerland. This article is an open access article distributed under the terms and conditions of the Creative Commons Attribution (CC BY) license (https:// creativecommons.org/licenses/by/ $4.0 /)$.
Faculty of Bioeconomy, Novia University of Applied Sciences, Raseborgsvägen 9, 10600 Raseborg, Finland; farid.karimi@novia.fi

\begin{abstract}
According to EU goals and the Paris Agreement, an urgent need exists for reducing $\mathrm{CO}_{2}$ emissions while still securing energy supply. Thus, the timely deployment of carbon capture and storage (CCS) is seemingly unavoidable, especially for the cement and steel industries. However, diverse perceptions of CCS among stakeholders such as experts, politicians, and laypeople exist that could hinder the deployment of the technology. Hence, it is worthwhile to recognise these diverse perceptions and their roots. In the studies on risk perceptions, the emphasis has been mostly on the public, as well as factors that influence the public, such as knowledge dissemination and trust. Although these are crucial elements, they are not enough to explain the complexity of risk perceptions. In contrast to the mainstream research, this paper hypothesises that both laypeople and experts are affected by common cultural denominators, therefore, might have similar patterns of risk perceptions. This research suggests a framework that explains the role of societal culture in risk governance, arguing that thrifty, uncertainty avoidant, hierarchical societies tend to have a higher risk perception of CCS. This study is based on a synthesis of the earlier research, an extensive literature review, and an analysis of interviews data.
\end{abstract}

Keywords: CCS; culture; risk perception; laypeople; social acceptance; experts

\section{Introduction}

According to EU goals [1] and the Paris Agreement [2], an urgent need exists for reducing $\mathrm{CO}_{2}$ emissions in EU states while still securing energy supply in order to mitigate climate change. Thus, the timely implementation of clean energy technologies such as carbon capture and storage (CCS) or carbon capture, utilisation and storage (CCUS) is seemingly crucial in the near future. CCS is needed not only because the supply of energy from fossil fuels will continue in many countries [3], but also because CCS is one of the main solutions to decarbonise cement and steel production. IEA states that 'CCS must be part of a strengthened global climate response' [4] (p. 12). Countries that are critically dependant on fossil fuels for energy security and economic development, as well as those which possess significant cement or steel industries, have been keen on the technology. Norway, the Netherlands, Sweden (The recent climate policy of Sweden highlighted CCS (accessed on 1 September 2021): https:/ / www.regeringen.se/rattsliga-dokument/statens-offentligautredningar/2020/01/sou-20204/) and the UK are prominent examples of countries in Europe where governments have considered the role of CCS and CCUS in their climate policy, e.g., [5]. Each stage of CCS technology involves a fairly high level of technological expertise, and some stakeholders do not consider the whole system to be commercially viable yet for large-scale deployment [6,7]. Moreover, there are uncertainties and concerns regarding policy issues, liability and public acceptance of CCS [6,8,9].

However, diverse perceptions of the technology among stakeholders such as politicians, laypeople, and experts in various countries exist that could hinder the deployment of technology even further, e.g., [10,11]. Hence, it is worthwhile to recognise these diverse perceptions and their roots. 
We are currently in the post-Paris paradox: despite the success of the conference, the current situation regarding tackling climate change is fairly obscure. It seems there is a lack of timely action against climate change [12] because we are constrained by several factors such as fragmented governance, economic issues [13], lack of trust in some stakeholders, lack of knowledge, various perceptions and different values attributed to societal culture, e.g., [14-18]. That said, recently, some promising targets have been set by some countries to materialise and foster the Paris Agreement [19].

In the studies on risk perceptions of energy technologies, the emphasis has been mostly on the public, as well as factors that influence the public, such as knowledge dissemination and trust, e.g., $[6,20,21]$. Although these are crucial elements, they are not enough to explain the complexity of risk perceptions of stakeholders. Moreover, it is problematic to assume that it is mainly laypeople having misperceptions or making wrong decisions that consequently hinder the development and deployment of technology. Glanz and Schönauer [22] (p. 3) claim that "experts represent dominant social perceptions and reflect chances and risks for acceptance". In contrast to much of the mainstream research on risk perceptions that mainly use case studies in the realm of environmental and health issues, e.g., [23-25], this paper hypothesises that both laypeople and experts are affected by common cultural denominators and therefore might have a fairly similar pattern of risk perceptions vis-à-vis controversial energy systems such as CC(U)S. Comparative studies on CCS risk perceptions between experts and laypeople are scarce. However, van Heek et al. [26] (p. 7222) conducted a study on both laypeople and experts in the case of carbon dioxide utilisation (CDU), suggesting: it is also highly probable that country-specifically and cultured attitudes influence CDU product acceptance and therefore, a country- and culture-specific comparison of CDU product acceptance should also be addressed in further research. In addition, Mander et al. [27] report some similarities between experts and laypeople risk perceptions of CCS. This paper aims to fill this research gap.

This study is based on an extensive literature review, synthesis of three earlier papers of the author [28-30] which the cultural hypothesis on the public and experts were developed separately and discourse analysis of semi-structured in-depth interviews. This research is a country-level comparative study between laypeople and experts.

The next section is a discussion on data and research methods. It follows with the survey of the relevant and updated literature on risk perceptions of CCS in order to highlight the existing research gap and support the hypothesis of this paper. Then, the concept of societal culture is scrutinised and the concept of common cultural denominators is defined. Next, the results of the analysis and limitations of the study are discussed. Finally, this paper ends with conclusions and, some recommendations for further research.

\section{Material and Methods}

This paper is interpretive research [31] based on the qualitative synthesis of three articles of the author that through qualitative and quantitative methods hypothesis the impact of culture on risk perceptions of laypeople [28,29] and experts [30] separately, supplemented by an extensive literature review on risk perceptions of CCS. Furthermore, a discourse analysis of 19 semi-structured depth interviews with CCS experts in Germany, Norway and Finland was conducted.

When it comes to synthesis analysis, this study used critical interpretive synthesis (CIS) as the study deal with 'a complex and diverse body of research' [32,33]. Synthesis analysis provides 'building blocks for the theory that helps us to understand and explain' the topic of research [33] (p. 183). This method aims to produce a theory, or reconceptualise existing theories and research [34]. Furthermore, CIS is a methodology with an 'explicit orientation to theory generation particularly when the body of evidence is very complex' [33] (p. 213). Moat et al. [35] (p. 617) argue that CIS could help to understand 'how context and issues influence policymakers' and stakeholders' views. The advantage of CIS is that this method utilises various types of data such as quantitative and qualitative studies, theoretical work, case studies, and policy documents [35-37]. This paper indeed 
used mixed data. Furthermore, a complementary literature review is suggested as a useful methodological approach to evaluate a theory in a certain area by exploring "the collective evidence" in this "certain research area" [38] (p. 334). When it comes to the interviews, individuals from governmental bodies, research institutes, energy companies and NGOs were interviewed. The interviews provided insights into CCS risk perceptions of experts. I employed discourse analysis to untangle the risk perceptions of experts. Røyrvik et al. [39] suggest that discourse analysis reveals "our perception". Narratives are the construct of "perceptual lenses" of actors whose cultural factors (e.g., values and beliefs) influence these perceptions [40,41]. Glanz and Schönauer [22] (p. 3) state that experts' "positions and conflicts are assumed to be crucial for the formation and progress of social debates and public discourses".

In sum, the aforementioned methods and materials are used to examine whether similarity exists between risk perceptions of laypeople and experts and what (unheeded) factor might affect their perceptions similarly.

\section{Risk Perception: An Overview}

The focus of this research is mainly on socio-cultural risk theory and the social construction of risk. Some significant studies show the import role of cultural values in risk perception of technology, mainly based on the cultural theory (CT) of Mary Douglas [42-49].

Douglas and Wildavsky [43] state that people emphasise some risks and ignore others. Moreover, each society has its very own understanding that decides what is of concern, how to deal with the risk, and what should be given higher priority (ibid). Hence, when it comes to risk, societies are selective. Johnson and Covello [44] elaborate on Douglas and Wildavsky's theory that it is not nature that influences societies to choose and perceive what is risky, but rather it is predominately cultural and societal factors that affect their determination of risk. Dake [42] asserts that risk preferences and perceptions and 'interpretation of natural phenomena' are social constructions of culture. Moreover, Nelkin [50] argues that risk is partly a social construction and risk evaluation is thus a 'social process'. Fitchen et al. [51] used a holistic approach utilising a case study to show the complexity of risk perception and that 'the local context in which the risk is embedded' influences the risk. Brown [52] argues that some factors, such as psychological ones, are not capable of explaining risk perception entirely since risk perception stems from social norms. Hence, he highlights the role of social and cultural factors.

Nonetheless, these groundbreaking but dated scholarships focus on generic aspects of culture that have little to do with societal characteristics. These studies concern the degree that an individual belongs to a social group and is constrained by social rules in a community. In addition, some scholars express scepticism about CT, claiming that dimensions of Douglasian CT are not successful or inclusive to explain risk perception and cultural orientations. They suggest further research for a new comprehensive approach [53-55].

Jasanoff $[56,57]$ claims the role of culture in risk perception as 'crucial' and that these cultural factors even shape 'scientific aspects of risk assessment'. She supports her social constructionist approach to risk using a comparative study between the US and the UK arguing that national culture affects not only the risk perception of the public but also of policymakers and scientists [56].

This paper considers societal culture to distinguish one nation from another. To the best of my knowledge, except Jasanoff [56], all the aforementioned scholarship categorise culture within a community or nation which is mainly an anthropological approach.

\subsection{Risk Perceptions of CCS: State of the Art}

In the following, the identified factors that influence risk perceptions of CCS are discussed and categorised. However, studies on the comparison between CCS risk perceptions of experts and laypeople are scarce. 


\subsubsection{Trust in Stakeholders}

Trust in main stakeholders such as government is an important factor in risk perception and acceptance of technology [16,58-68]. Trust in research and academic sectors and NGOs is consistently ranked high. Consequently, the public rely on what they advocate or verify and prefer to involve with them in decision-making processes rather than stakeholders from industry $[6,58,63,69]$.

Terwel et al. [62] and Tcvetkov et al. [6] argue that higher trust in stakeholders leads to lower risk perception. Nevertheless, Terwel et al. [62] differentiate between two types of trust: integrity-based and competence-based. Integrity-based trust concerns trust form around the honesty and good reputation of stakeholders. Competence-based trust refers to trust that is based on the expertise of stakeholders. Terwel et al. [62] claim that the public have more positive opinions about CCS, whether competence-based trust in stakeholders who support CCS is high. By contrast, the negative public opinion increases if integritybased trust in proponents of CCS is low (ibid).

Notwithstanding the majority of literature highlighting the direct role of trust in risk perception, Wallquist et al. [66] discuss how convictions and trust affect people's perceptions of CCS in a causal way. They claim that while convictions concerning issues such as $\mathrm{CO}_{2}$ abatement influence risk perception, trust is not a significant factor. However, Wallquist et al. [66] state that if the public could realise and differentiate the role of each stakeholder, trust will eventually become influential.

\subsubsection{Communication}

Information and knowledge seemingly impact risk perception of technology, e.g., [5,6,26,70-73]. Through social experiments and questionnaires, researchers have estimated the effect of providing information on the public's risk perception. Depending on the methods involved, results have varied both in magnitude and direction, with positive, negative and non-significant results, e.g., [70]. Generally, CCS knowledge among the public is considerably low, e.g., [65,68,73]. De Best-Waldhober et al. [70] claim that uninformed people have volatile opinions. Their results demonstrate that people reluctantly accept CCS after being provided with enough information from experts.

Methods of communication and outreach, the procedure of dissemination, and the content of communication with stakeholders all have different levels of impact on risk perception, e.g., [20,73-81]. For instance, Wallquist et al. [73] argue that if engineering and communication experts inform the public about the properties and effect of $\mathrm{CO}_{2}$ on the environment, concern over $\mathrm{CO}_{2}$ leakage would likely decrease. Bruin et al. [76] propose the following measures for effective communication: informing the public about alternative technologies to CCS, using simple wording for communication concerning the technology and avoiding jargon, and timely communication procedures. Moreover, Ashworth et al. [74] recommend involving NGOs in the communication about CCS and preparation of communication materials, as well as developing a range of mediums for communication.

Finally, some studies claim that knowledge and information do not play a key role in reducing risk aversion of new and emerging technologies because the public's reactions incorporate other factors beyond technical properties, e.g., [44,79,82].

\subsubsection{Community Characteristics}

The localities of the proposed facilities affect the risk perception of CCS, e.g., [82-85]. Furthermore, the Not In My Backyard (NIMBY) concept is considered as a factor that shapes a local community's risk perception and social acceptance of CCS, e.g., [6,22,64,86-89]. Moreover, other factors such as proximity, community compensation and local residents economic losses or decreases in real estate value are considered influential in CCS risk perception, e.g., [87-94]. NIMBY reactions are attributable to individual values, concern over the safety of CCS and economic benefits of the community [88]. It seems owning a dwelling affects CCS risk perception on the local level, while it has less impact on the national CCS acceptance level (ibid). 
Some researchers discuss NIMBYism, or concerns about proximity or real estate for specific case studies such as the Netherlands, e.g., [59,78,90] and Germany [86]. For instance, Terwel et al. [90] based on a survey argue that people in Barendrecht were concerned about the possible fall in local property value vis-à-vis the projected CCS facility. Braun [86] (p. 2272) emphasises NIMBY reactions to CCS: 'living in or next to a county with a potential CCS site significantly reduces the acceptance of CCS'.

However, Terwel and Daamen (2014) (p. 298) claim that 'the psychological structure of initial attitudes towards CCS' is relatively similar for both onsite and offsite people in the same country. Huijts et al. [59] argue that local negative opinions about CCS are not necessarily ascribed to NIMBYism. Furthermore, Wolsink [95] and Burningham [96] claim that the NIMBY concept 'tarnish[es]' those who oppose or have opinions about a siting-related development.

Lastly, some scholarships discuss the effects of community characteristics on risk perception beyond NIMBYism and place attachment, e.g., [71,97-100]. For instance, Bradbury et al. [100] and Bradbury [99] argue differences in cultural and socioeconomic features of a community as a factor that affects perception of CCS. Anderson et al. [97] claim human and social capital features, as well as experience of similar facilities, such as gas pipelines, affect perception and social acceptance of CCS within local communities.

\subsection{Unheeded Factor: Societal Culture}

Sala and Oltra [101] highlight that values influence experts' risk perception of CCS. Karimi et al. [28], Karimi and Toikka [29] and Karimi and Komendantova [30] argue that risk perceptions of CCS are a more complex process, incorporating another factor in parallel with the aforementioned factors-societal culture. These studies argued that societal culture affects some of the other factors, such as trust. This paper analyses this hypothesis further for both laypeople and experts comparatively. As it appears in the survey of the literature, there is a deficiency in comparative studies between laypeople and experts vis-à-vis risk perceptions of CCS.

Before scrutinising the hypothesis of this paper, first, I suggest a definition for common cultural denominators in the following section.

\section{Definition of Culture}

When it comes to culture, two fundamental questions exist that are not simple to address: what precisely culture is and how it is constructed. Culture is an abstract construct. Furthermore, there are various approaches to study and stipulate culture within and between academic fields. Therefore, a sole, straightforward answer for these questions is near nonexistence. To address this, Thompson et al. [102] and Minkov [103] suggest that what a scholar has to do when they deal with the concept of culture is to define clearly what culture is, how they conceptualise and measure it. Moreover, a scholar ought to elucidate the operationalisation of the cultural approach that they employ. Whereas anthropologists have been systematically theorising culture for almost a century, e.g., [104-109], scholars of other areas only realised the concept of culture decades later, e.g., [110-114].

One enduring definition describes culture as 'patterned ways of thinking, feeling and reacting, acquired and transmitted mainly by symbols, constituting the distinctive achievements of human groups, including their embodiments in artefacts; the essential core of culture consists of tradition (i.e., historically derived and selected) ideas and especially their attached values' [107] (p. 86).

Culture has visible and invisible facets [103]. The invisible facet of culture exists in our mind, e.g., values [115]. The visible side of culture is manifested in human behaviour and social interactions. In addition, elements of culture comprise values [107,115], beliefs [116], attitudes [104], norms [117] and symbols [115,118] (Figure 1). Values are conceptions of desirables that affect actions and are attributable to a characteristic of a group [107]. Beliefs are 'social axioms' about spiritual or physical worlds [116] and 'about the relationship between two entities or concepts' [119] (p. 289). Attitudes are the public's assessments about 
something [102]. Norms are values that the public wish to see in others' behaviour [103]. My definition of symbols is those complex features that derive from and are affected by language in one way or another.

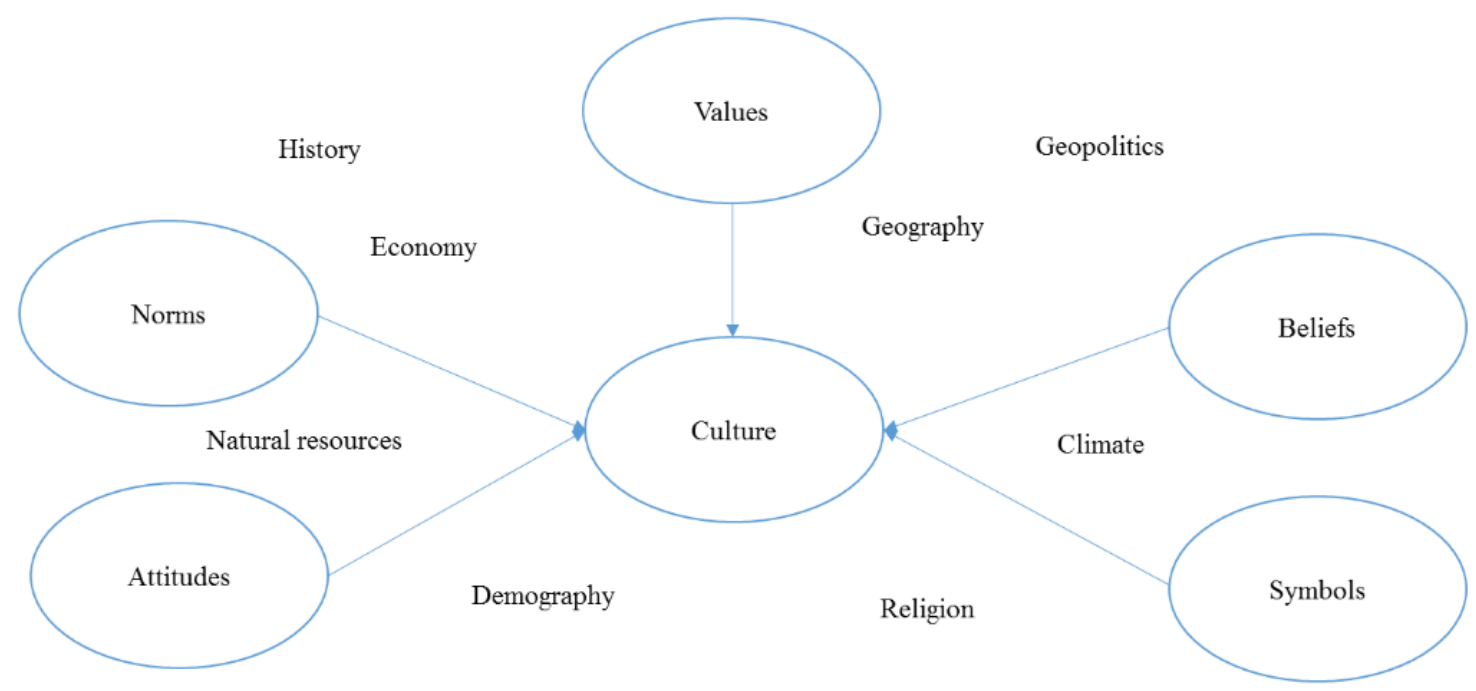

Figure 1. Construction and elements of culture (Source: Author). Blue ovals are elements of culture and factors that explicitly or implicitly affect all elements of culture are in the background.

This present study introduces the concept of common cultural denominators that is 'the collective programming of the mind' [115], such as shared societal values which distinguishes the members of one society from another.

I distinguish between situational attitudes and cultural values. A common misperception exists about situational attitudes, cultural values and cultural products (i.e., cultural implications). By and large, the rate of change in cultural values is very slow and does not happen over a couple of decades $[55,120]$. By contrast, situational attitudes are dynamic traits (e.g., a fad) that fluctuate even in a relatively short period of time. Maleki [121] and Maleki and Hendriks [55] argue that some studies have flaws due to a lack of distinction between situational attitudes and cultural values. Moreover, one should not mix 'objective culture' with the concept of common cultural denominators that I introduce in this research. Objective culture is what we see as institutions such as laws, or for instance, artefacts and objects $[103,115,122]$.

\section{Discussion}

By using the largescale Eurobarometer survey on CCS [69] and Hofstede cultural dimensions, Karimi et al. [28] and Karimi and Toikka [29] argue that thrifty (this present study interpreted the long term orientation (LTO) dimension of Hofstede as thriftiness. However, LTO is a 'big dimension' that measures other cultural features as well [123]) and hierarchical nations with high uncertainty avoidance tend to a higher level of CCS risk perception. These cultural features could also influence trust towards stakeholders and actors such as decision-makers.

Comparing the results of Karimi et al. [28] and Karimi and Toikka [29] of laypeople with Karimi and Komendantova [30] of experts, interestingly, it seems that similarities exist between risk perceptions of experts and laypeople in the three countries of the case studies (i.e., Germany, Norway and Finland), possibly influenced by their common cultural denominators $[43,49,124]$ (Figure 2). Furthermore, this is in line with Johnson and Covello [44] and Jasanoff [56] who state that 'experts are themselves culture bound' and they share the basic characteristics with laypeople as both are influenced by the same cultural and social circumstance. For example, Germany is a relatively hierarchical, highly thrifty society with a high level of uncertainty avoidance: all features that could lead to high-risk perception. 


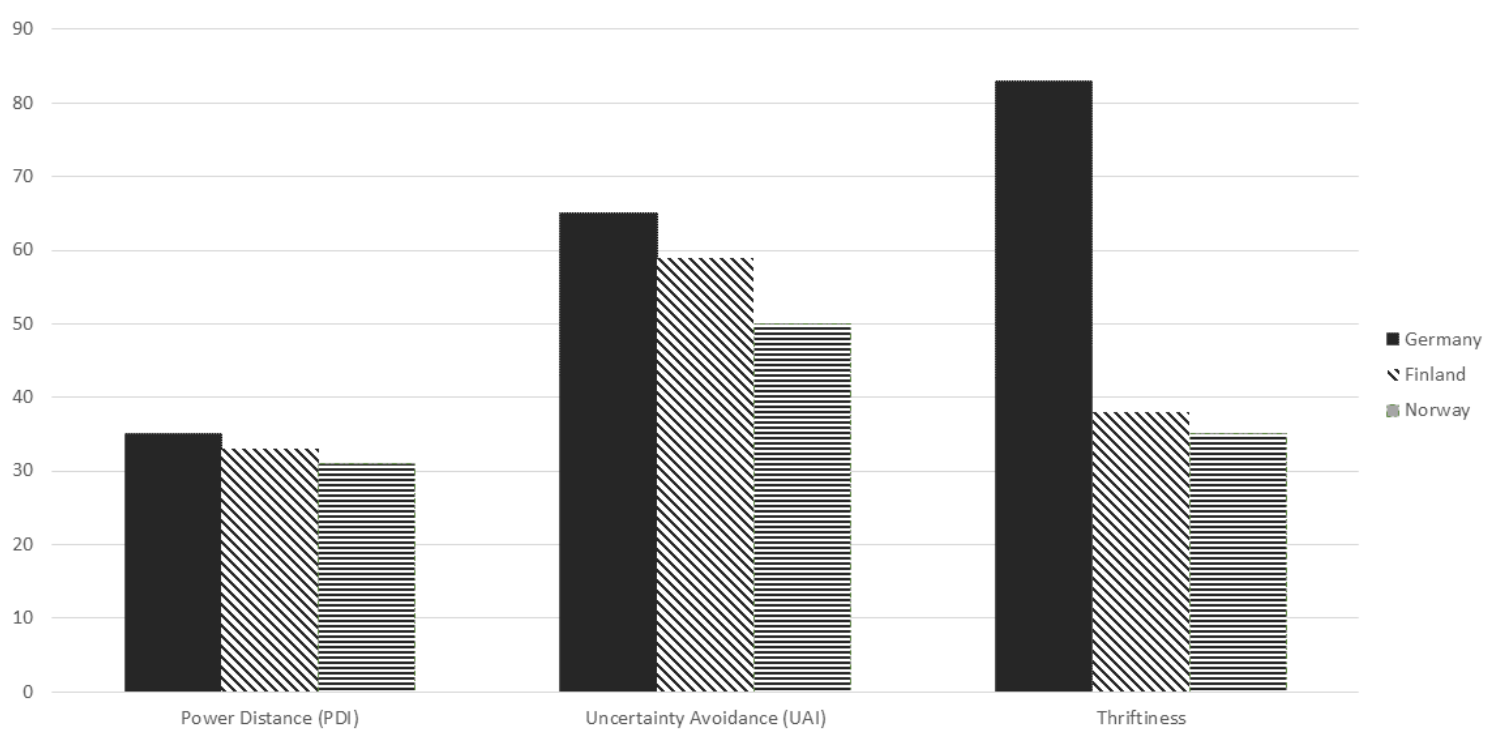

Figure 2. Cross-cultural scores of Germany, Finland and Norway (data source: [125]).

The results of discourse analysis on experts and, for instance, Eurobarometer [69], Braun [86] and Glanz and Schönauer [22] support the hypothesis that in Germany, relatively homogenous strong opposition exists among laypeople and experts. For instance, only $23 \%$ of German respondents perceived CCS as an effective technology to tackle climate change [69]. Furthermore, only $10 \%$ of the German respondents believed that they would benefit from CCS deployment (ibid). Both are the lowest percentages amongst the countries of the study. Moreover, $81 \%$ of respondents in Germany were worried about the environmental impacts of CCS deployment, the highest percentage amongst countries measured (ibid). Braun [86] and Glanz and Schönauer [22] argue that there are a high-risk perception and 'strong' public opposition against CCS in Germany. In addition, German experts interviewed commonly claim that CCS is not a useful technology. Merely a couple of the experts tentatively mentioned that only for industrial sectors (e.g., cement and steel industries) CCS might be useful. For example, in one of the interviews a scientist in Germany expressed:

'I think people should be more intelligent to put a lot of tons of $\left[\mathrm{CO}_{2}\right]$ under the earth for a long time... there should be more wise ways to produce [clean] energy than [CCS]. We should concentrate more on renewable energy systems in the long run.'

Interestingly, an interviewee from an NGO in Germany claimed that discussions about Bioenergy with Carbon Capture and Storage (BECCS) are a 'hoax'. My claim regarding Germany is also in accord with Glanz and Schönauer [22] who report similar high-risk perceptions between both experts and the public through conducting a discourse analysis of similar German stakeholders to the current study. Similar patterns of perceptions are observed by van Heek et al. [26] on CDU in a comparative study between laypeople and experts.

The present study, however, identifies a low level of risk perception amongst both experts and laypeople in Norway in sharp contrast to Germany. The theory of this paper suggests that the low risk perception in societies like Norway is to some extent attributable to the significantly low-hierarchical, non-thrifty, low uncertainty-avoidance culture, of course, in addition to other geographical, political and socio-economic factors [28,29]. Social acceptance (and somehow acceptability) of CCS in Norway is almost the highest among the European countries sampled (ibid). The result of the discourse analysis suggests relatively significant low CCS risk perception and high support amongst experts in Norway. It is evident that stakeholders in Norway are over-optimists [126]. This has even led to miscalculations in the development and deployment of CCS projects in some cases. For example, an interviewee claimed:

'If you do not take CCS seriously, you do not take climate change seriously.' 
Another interviewee stated that timely large scale deployment of CCS is unavoidable: 'It is a matter of when, not if.'

Lastly, one of the interviewees claimed:

'It is kind of naive to think that we can [tackle climate change] without CCS, especially in the current situation in which fossil fuel usage increases'.

The results of the analysis of interviews data are in line with the Haug and Stigson [87] study that shows very positive attitudes to CCS exist in Norway among various stakeholders.

In Finland, most stakeholders who were interviewed showed a relatively low-risk perception of CCS. Similarly to Kojo and Innola [127] regarding BECCS and mineral carbonation, this present study observed fairly positive perceptions among the experts:

'At the moment if you want to reduce $\mathrm{CO}_{2}$ emissions properly, say, at coal power stations or in coal-intensive industries, in practice, the only possibility is CCS.'

Nevertheless, some of the interviewees claimed that Finland would not need CCS in order to meet its climate goals:

'Finland can reach its desired level of low-emission without CCS.'

Karimi et al. [28] and Karimi and Toikka [29] show that the risk perception of laypeople in Finland nearly follows a similar trend as the experts described above. According to Eurobarometer [69], CCS risk perception and the level of concerns over the technology in Finland were one of the lowest among EU countries. Pihkola et al. [128] also report a 'neutral' attitude of Finnish stakeholders towards CCS. Similarly, Rodriguez et al. [129] also observed social acceptance of BECCS is not a challenge in Finland, confirmed by Finnish experts. A thorough analysis of Finnish print media in the period of 1996-2015 by Kojo and Innola [127] shows that $60 \%$ of CCS-related items articulated CCS positively and only $14 \%$ of items were negative (cf. over $66 \%$ of items in German media were negative about CCS, and merely $6 \%$ were positive [130]). The rest of the items in the Finnish media had either neutral or mixed stances on CCS [127].

Some research conducted outside of Europe, such as Sun et al. [72] for the case of China, also reports similarities between CCS perceptions of experts and the public. In sum, several factors influence the variation of risk perceptions among nations, including geographical, societal, economic, political, historical and technical settings for the deployment of CCS. However, the factors mentioned above also eventually construct and form the common cultural denominators of a country, one way or another (Figure 1). This study discerns a fairly similar pattern of risk perceptions of CCS between experts and laypeople, seemingly attributable to the common cultural denominators in parallel with the other factors discussed in Section 3.

\section{Limitations of the Study}

One of the main data sources for this research is the Eurobarometer survey Public Awareness and Acceptance of $\mathrm{CO}_{2}$ Capture and Storage that was published in 2011. Nonetheless, there is no updated large-scale survey conducted after that. Thus, while this old data might challenge the result of this study, this paper tried, similarly to d'Amore et al. [82], to support the hypothesis and claims with updated literature as well as checking the data with other sources. For instance, according to Eurobarometer [69], the majority of respondents expressed that conventional outlets such as newspapers are their main source of information. A recent survey in Finland confirms that such outlets are still the main source of information to the public, not least for scientific-related news [131].

I acknowledge that societal factors are much more nuanced than only common cultural denominators. Hence, the proposed cultural framework in this study should be taken into consideration merely alongside other factors such as trust, providing information, political setting and knowledge dissemination.

The author also recognises that CCS opinions are volatile, and all we have are projected opinions at the time of surveying. This hinders far-reaching conclusions about the impacts of common cultural denominators on risk perception. There is a possibility that opinions 
could change over time. Therefore, the Eurobarometer data are likely based on labile opinions that could be changed for some other known and unknown reasons.

Finally, using non-homogenous and asymmetric research methods and data for studying laypeople and experts could challenge the results of this study. That said, this study tried to support its claims concerning laypeople with existing literature as well.

\section{Conclusions}

Research on the risk perceptions of new energy technologies and people's reactions to them in various countries needs to account for the different technical and natural settings as well as how differences in where people live build their values and worldviews, and shape their opinions. When it comes to CCS, the identified factors in the existing literature that influence risk perceptions could be broadly categorised into trust, communication and community characteristics. Although these factors are all important in affecting risk perception, this paper argued that common cultural denominators are as important; these are macro-level societal factors such as commonly shared values affecting risk perception of all stakeholders. In other words, both experts and laypeople are affected by common cultural denominators; consequently, they might have a relatively similar pattern of risk perceptions. Moreover, common cultural denominators help us realise the relationship between laypeople's and experts' stances towards CCS.

It is evident that the consideration of societal factors is important in the development of new energy technologies and risk governance of energy transition in general. This paper suggests that thrifty, uncertainty avoidant, hierarchical societies tend to have higher risk perception of technologies such as $\mathrm{CC}(\mathrm{U}) \mathrm{S}$. These cultural features are also related to trust towards various stakeholders. These factors should not be underestimated during the policymaking and deployment of projects. This paper recommends that stakeholders such as industry and policymakers consult on these matters in every step during the planning and communication phases of a project, e.g., in order to increase the accuracy of their risk assessment of a project. Therefore, the framework that is introduced in this research could provide a toolkit for risk assessment. Some stakeholders could benefit from the framework to operationalise risk perception by utilising the seemingly overlooked impact of common cultural denominators when dealing with the risks and uncertainties of new energy technologies such as $\mathrm{CC}(\mathrm{U}) \mathrm{S}$. The strength of the framework attributes to the fact that international organisations weigh societal specifications in their planning and resource allocation. For example, the European Commission might benefit from the framework for budget allocation and communication with member states to implement CCS projects.

While this study has observed similarities between risk perception of laypeople and experts who are under the influence of common cultural denominators, it seems that laypeople have somewhat ambivalent yet volatile opinions towards technology due to some factors such as lack of knowledge. Therefore, their risk perception should be malleable depending on their common cultural denominators, in addition to other factors such as trust and knowledge dissemination, e.g., [26]. Moreover, this paper does not disregard the impacts of individual values, benefits and interests on stakeholders' risk perceptions.

Finally, a need exists for further comparative research to examine the hypothesis of this paper systematically. If the risk perception of experts and the public could be replicated to be similar attributable to the common cultural denominators, then the direction of future research on the social acceptability of, and public engagement in, technology deployment might change fundamentally. If we assume that risk perceptions of experts and the public are similar, future research is recommended to focus on stakeholder acceptance or acceptability rather than social acceptance.

Funding: The APC was funded by Novia University of Applied Sciences.

Institutional Review Board Statement: Not applicable.

Informed Consent Statement: Not applicable. 
Data Availability Statement: The data presented in this study are available on request from the corresponding author. The data are not publicly available due to privacy.

Acknowledgments: I acknowledge the support of the 2019 workshop on the EU's climate and energy policy organised by Working Group 2 of the COST Action (CA17119) and RouteCCS project funded by the Swedish Institute.

Conflicts of Interest: The author declares no conflict of interest.

\section{References}

1. European Commission. A European Green Deal; European Commission: Brussels, Belgium, 2020. Available online: https: / / ec.europa.eu/info/strategy / priorities-2019-2024/european-green-deal_en (accessed on 1 September 2021).

2. UNFCCC. The Paris Agreement; UN: Bonn, Germany, 2016. Available online: https://unfccc.int/process-and-meetings/the-parisagreement/the-paris-agreement (accessed on 1 September 2021).

3. IEA. World Energy Outlook 2019; IEA: Paris, France, 2019.

4. IEA. 20 Years of Carbon Capture and Storage-Accelerating Future Deployment; International Energy Agency: Paris, France, 2016.

5. Akerboom, S.; Waldmann, S.; Mukherjee, A.; Agaton, C.; Sanders, M.; Kramer, G.J. Different this time? The prospects of CCS in the Netherlands in the 2020s. Front. Energy Res. 2021, 9, 193. [CrossRef]

6. Tcvetkov, P.; Cherepovitsyn, A.; Fedoseev, S. Public perception of carbon capture and storage: A state-of-the-art overview. Heliyon 2019, 5, e02845. [CrossRef]

7. Smith, P.; Davis, S.J.; Creutzig, F.; Fuss, S.; Minx, J.; Gabrielle, B.; Kato, E.; Jackson, R.B.; Cowie, A.; Kriegler, E.; et al. Biophysical and economic limits to negative $\mathrm{CO}_{2}$ emissions. Nat. Clim. Chang. 2016, 6, 42-50. [CrossRef]

8. IEA. Five Keys to Unlock CCS Investment-Analysis; International Energy Agency: Paris, France, 2018.

9. Fuss, S.; Lamb, W.F.; Callaghan, M.W.; Hilaire, J.; Creutzig, F.; Amann, T.; Beringer, T.; Garcia, W.D.O.; Hartmann, J.; Khanna, T.; et al. Negative emissions-Part 2: Costs, potentials and side effects. Environ. Res. Lett. 2018, 13, 063002. [CrossRef]

10. Romanak, K.; Fridahl, M.; Dixon, T. Attitudes on carbon capture and storage (CCS) as a mitigation technology within the UNFCCC. Energies 2021, 14, 629. [CrossRef]

11. Parmiter, P.; Bell, R. Second Report of the Thematic Working Group on: Policy, Regulation and Public Perception; The CCUS Projects Network: Oslo, Norway, 2020; p. 28.

12. Cornwall, W. Five years in, Paris pact still a work in progress. Science 2020, 370, 1390. [CrossRef]

13. Tanaka, K.; Boucher, O.; Ciais, P.; Johansson, D.J.A.; Morfeldt, J. Cost-effective implementation of the Paris Agreement using flexible greenhouse gas metrics. Sci. Adv. 2021, 7, eabf9020. [CrossRef] [PubMed]

14. Arroyo-Currás, T.; Bauer, N.; Kriegler, E.; Schwanitz, V.J.; Luderer, G.; Aboumahboub, T.; Giannousakis, A.; Hilaire, J. Carbon leakage in a fragmented climate regime: The dynamic response of global energy markets. Technol. Forecast. Soc. Chang. 2015, 90, 192-203. [CrossRef]

15. Downie, C. Steering Global Energy Governance: Who Governs and What Do They Do? Regul. Gov. 2020, 90, 192-203. [CrossRef]

16. Moon, W.-K.; Kahlor, L.A.; Olson, H.C. Understanding public support for carbon capture and storage policy: The roles of social capital, stakeholder perceptions, and perceived risk/benefit of technology. Energy Policy 2020, 139, 111312. [CrossRef]

17. Requier, F.; Fournier, A.; Rome, Q.; Darrouzet, E. Science Communication Is Needed to Inform Risk Perception and Action of Stakeholders. J. Environ. Manag. 2020, 257, 109983. [CrossRef] [PubMed]

18. Rühlemann, A.; Jordan, J.C. Risk Perception and Culture: Implications for Vulnerability and Adaptation to Climate Change. Disasters 2021, 45, 424-452. [CrossRef]

19. Höhne, N.; Gidden, M.J.; Elzen, M.D.; Hans, F.; Fyson, C.; Geiges, A.; Jeffery, M.L.; Gonzales-Zuñiga, S.; Mooldijk, S.; Hare, W.; et al. Wave of net zero emission targets opens window to meeting the Paris Agreement. Nat. Clim. Chang. 2021, 11, 820-822. [CrossRef]

20. Arning, K.; Heek, J.O.-V.; Linzenich, A.; Kaetelhoen, A.; Sternberg, A.; Bardow, A.; Ziefle, M. Same or different? Insights on public perception and acceptance of carbon capture and storage or utilization in Germany. Energy Policy 2019, 125, 235-249. [CrossRef]

21. Arning, K.; Heek, J.O.-V.; Sternberg, A.; Bardow, A.; Ziefle, M. Risk-benefit perceptions and public acceptance of Carbon Capture and Utilization. Environ. Innov. Soc. Transit. 2020, 35, 292-308. [CrossRef]

22. Glanz, S.; Schönauer, A.-L. Towards a Low-Carbon Society via Hydrogen and Carbon Capture and Storage: Social Acceptance from a Stakeholder Perspective. J. Sustain. Dev. Energy Water Environ. Syst. 2021, 9, 1080322. [CrossRef]

23. Blok, A.; Jensen, M.; Kaltoft, P. Social identities and risk: Expert and lay imaginations on pesticide use. Public Underst. Sci. 2008, 17, 189-209. [CrossRef]

24. Zingg, A.; Siegrist, M. Lay people's and experts' risk perception and acceptance of vaccination and culling strategies to fight animal epidemics. J. Risk Res. 2012, 15, 53-66. [CrossRef]

25. Hartmann, C.; Hübner, P.; Siegrist, M. A risk perception gap? Comparing expert, producer and consumer prioritization of food hazard controls. Food Chem. Toxicol. 2018, 116, 100-107. [CrossRef]

26. Van Heek, J.; Arning, K.; Ziefle, M. Differences between laypersons and experts in perceptions and acceptance of co2-utilization for plastics production. Energy Procedia 2017, 114, 7212-7223. [CrossRef] 
27. Mander, S.; Polson, D.; Roberts, T.; Curtis, A. Risk from CO2 storage in saline aquifers: A comparison of lay and expert perceptions of risk. Energy Procedia 2011, 4, 6360-6367. [CrossRef]

28. Karimi, F.; Toikka, A.; Hukkinen, J.I. Comparative socio-cultural analysis of risk perception of Carbon Capture and Storage in the European Union. Energy Res. Soc. Sci. 2016, 21, 114-122. [CrossRef]

29. Karimi, F.; Toikka, A. General public reactions to carbon capture and storage: Does culture matter? Int. J. Greenh. Gas Control 2018, 70, 193-201. [CrossRef]

30. Karimi, F.; Komendantova, N. Understanding experts' views and risk perceptions on carbon capture and storage in three European countries. GeoJournal 2015, 82, 185-200. [CrossRef]

31. Bhattacherjee, A. Social science research: Principles, methods, and practices. In Global Text Project; University of South Florida: Tampa, FL, USA, 2012.

32. Barnett-Page, E.; Thomas, J. Methods for the synthesis of qualitative research: A critical review. BMC Med. Res. Methodol. 2009, 9, 59. [CrossRef] [PubMed]

33. Schick-Makaroff, K.; Macdonald, M.; Plummer, M.; Burgess, J.; Neander, W. What synthesis methodology should i use? A review and analysis of approaches to research synthesis. AIMS Public Health 2016, 3, 172-215. [CrossRef] [PubMed]

34. Dixon-Woods, M.; Cavers, D.; Agarwal, S.; Annandale, E.; Arthur, A.; Harvey, J.; Hsu, R.; Katbamna, S.; Olsen, R.; Smith, L.; et al. Conducting a critical interpretive synthesis of the literature on access to healthcare by vulnerable groups. BMC Med Res. Methodol. 2006, 6, 1-13. [CrossRef]

35. Moat, K.A.; Lavis, J.N.; Abelson, J. How contexts and issues influence the use of policy-relevant research syntheses: A critical interpretive synthesis. Milbank Q. 2013, 91, 604-648. [CrossRef] [PubMed]

36. Heaton, J.; Corden, A.; Parker, G. 'Continuity of care': A critical interpretive synthesis of how the concept was elaborated by a national research programme. Int. J. Integr. Care 2012, 12. [CrossRef]

37. Flemming, K. Synthesis of quantitative and qualitative research: An example using Critical Interpretive Synthesis. J. Adv. Nurs. 2009, 66, 201-217. [CrossRef]

38. Snyder, H. Literature review as a research methodology: An overview and guidelines. J. Bus. Res. 2019, 104, 333-339. [CrossRef]

39. Røyrvik, J.; Olsen, M.S.; Aasen, T. Political rationality and CCS discourse. Energy Procedia 2012, 23, 284-295. [CrossRef]

40. Ney, S. Resolving Messy Policy Problems: Handling Conflict in Environmental, Transport, Health and Ageing Policy, 1st ed.; Routledge: New York, NY, USA, 2009.

41. Ney, S. The governance of social innovation: Connecting meso and macro levels of analysis. In The Science of Stories; Jones, M.D., Shanahan, E.A., McBeth, M.K., Eds.; Palgrave Macmillan: New York, NY, USA, 2014; pp. 207-234. [CrossRef]

42. Dake, K. Myths of nature: Culture and the social construction of risk. J. Soc. Issues 1992, 48, 21-37. [CrossRef]

43. Douglas, M.; Wildavsky, A. Risk and Culture: An Essay on the Selection of Technological and Environmental Dangers, 1st ed.; University of California Press: Berkeley, CA, USA, 1982.

44. Johnson, B.B.; Covello, V.T. The Social and Cultural Construction of Risk: Essays on Risk Selection and Perception; Springer: Berlin/Heidelberg, Germany, 1987.

45. Kahan, D.M. The evolution of risk perceptions. Nat. Nanotechnol. 2009, 4, 705-706. [CrossRef] [PubMed]

46. Slovic, P. The Perception of Risk; Earthscan Publications: London, UK, 2000.

47. Stallings, R.A. Media discourse and the social construction of risk. Soc. Probl. 1990, 37, 80-95. [CrossRef]

48. Thompson, M.; Wildavsky, A. A proposal to create a cultural theory of risk. In The Risk Analysis Controversy; Kunreuther, H.C., Ley, E.V., Eds.; Springer: Berlin/Heidelberg, Germany, 1982; pp. 145-161.

49. Wildavsky, A.; Dake, K. Theories of risk perception: Who fears what and why? Daedalus 1990, 119, 41-60.

50. Nelkin, D. Communicating technological risk: The social construction of risk perception. Annu. Rev. Public Health 1989, 10, 95-113. [CrossRef]

51. Fitchen, J.M.; Heath, J.S.; Fessenden-Raden, J. Risk perception in community context: A case study. In The Social and Cultural Construction of Risk; Springer: Berlin/Heidelberg, Germany, 1987; pp. 31-54.

52. Brown, M.S. Communicating information about workplace hazards: Effects on worker attitudes toward risks. In The Social and Cultural Construction of Risk; Johnson, B.B., Covello, V.T., Eds.; Springer: Amsterdam, The Netherlands, 1987; pp. 251-274.

53. Sjöberg, L. Worry and risk perception. Risk Anal. 1998, 18, 85-93. [CrossRef]

54. Sjöoberg, L. Factors in risk perception. Risk Anal. 2000, 20, 1-12. [CrossRef]

55. Maleki, A.; Hendriks, F. Grid, group, and grade. Cross-Cult. Res. 2015, 49, 250-280. [CrossRef]

56. Jasanoff, S. Cultural aspects of risk assessment in Britain and the United States. In The Social and Cultural Construction of Risk; Johnson, B.B., Covello, V.T., Eds.; Springer: Amsterdam, The Netherlands, 1987; pp. 359-397. [CrossRef]

57. Jasanoff, S. Science and Public Reason, 1st ed.; Routledge: New York, NY, USA, 2012.

58. Williams, R.; Jack, C.; Gamboa, D.; Shackley, S. Decarbonising steel production using CO2 Capture and Storage (CCS): Results of focus group discussions in a Welsh steel-making community. Int. J. Greenh. Gas Control 2021, 104, 103218. [CrossRef]

59. Huijts, N.; Midden, C.J.; Meijnders, A.L. Social acceptance of carbon dioxide storage. Energy Policy 2007, 35, 2780-2789. [CrossRef]

60. Midden, C.J.H.; Huijts, N.M.A. The role of trust in the affective evaluation of novel risks: The case of $\mathrm{CO}_{2}$ storage. Risk Anal. 2009, 29, 743-751. [CrossRef]

61. Kaiser, M.; Zimmer, R.; Brunsting, S.; Mastop, J.; Pol, M. Development of CCS projects in Poland. How to communicate with the local public? Energy Procedia 2014, 51, 267-273. [CrossRef] 
62. Terwel, B.W.; Harinck, F.; Ellemers, N.; Daamen, D.D.L. Competence-based and integrity-based trust as predictors of acceptance of carbon dioxide capture and storage (CCS). Risk Anal. 2009, 29, 1129-1140. [CrossRef] [PubMed]

63. Terwel, B.W.; Harinck, F.; Ellemers, N.; Daamen, D.D. Going beyond the properties of CO2 capture and storage (CCS) technology: How trust in stakeholders affects public acceptance of CCS. Int. J. Greenh. Gas Control 2011, 5, 181-188. [CrossRef]

64. Terwel, B.W.; Daamen, D.D. Initial public reactions to carbon capture and storage (CCS): Differentiating general and local views. Clim. Policy 2012, 12, 288-300. [CrossRef]

65. Upham, P.; Roberts, T. Public perceptions of CCS: Emergent themes in pan-European focus groups and implications for communications. Int. J. Greenh. Gas Control 2011, 5, 1359-1367. [CrossRef]

66. Wallquist, L.; Visschers, V.H.M.; Dohle, S.; Siegrist, M. The Role of convictions and trust for public protest potential in the case of carbon dioxide capture and storage (CCS). Hum. Ecol. Risk Assess. Int. J. 2012, 18, 919-932. [CrossRef]

67. Braun, C.; Merk, C.; Pönitzsch, G.; Rehdanz, K.; Schmidt, U. Public perception of climate engineering and carbon capture and storage in Germany: Survey evidence. Clim. Policy 2018, 18, 471-484. [CrossRef]

68. Yang, L.; Zhang, X.; McAlinden, K.J. The effect of trust on people's acceptance of CCS (carbon capture and storage) technologies: Evidence from a survey in the People's Republic of China. Energy 2016, 96, 69-79. [CrossRef]

69. Eurobarometer. Public Awareness and Acceptance of $\mathrm{CO}_{2}$ Capture and Storage; Special Eurobarometer 364; European Commissiom: Brussels, Belgium, 2011.

70. De Best-Waldhober, M.; Daamen, D.; Faaij, A. Informed and uninformed public opinions on $\mathrm{CO}_{2}$ capture and storage technologies in the Netherlands. Int. J. Greenh. Gas Control 2009, 3, 322-332. [CrossRef]

71. Dowd, A.-M.; Itaoka, K.; Ashworth, P.; Saito, A.; de Best-Waldhober, M. Investigating the link between knowledge and perception of CO 2 and CCS: An international study. Int. J. Greenh. Gas Control 2014, 28, 79-87. [CrossRef]

72. Sun, Y.; Li, Y.; Cai, B.-F.; Li, Q. Comparing the explicit and implicit attitudes of energy stakeholders and the public towards carbon capture and storage. J. Clean. Prod. 2020, 254, 120051. [CrossRef]

73. Wallquist, L.; Visschers, V.; Siegrist, M. Impact of knowledge and misconceptions on benefit and risk perception of CCS. Environ. Sci. Technol. 2010, 44, 6557-6562. [CrossRef]

74. Ashworth, P.; Boughen, N.; Mayhew, M.; Millar, F. From research to action: Now we have to move on CCS communication. Int. J. Greenh. Gas Control 2010, 4, 426-433. [CrossRef]

75. Ashworth, P.; Wade, S.; Reiner, D.; Liang, X. Developments in public communications on CCS. Int. J. Greenh. Gas Control 2015, 40, 449-458. [CrossRef]

76. De Bruin, W.B.; Mayer, L.A.; Morgan, M.G. Developing communications about CCS: Three lessons learned. J. Risk Res. 2015, 18, 1-7. [CrossRef]

77. De Bruin, W.B.; Wong-Parodi, G. The role of initial affective impressions in responses to educational communications: The case of carbon capture and sequestration (CCS). J. Exp. Psychol. Appl. 2014, 20, 126-135. [CrossRef] [PubMed]

78. Brunsting, S.; Upham, P.; Dütschke, E.; Waldhober, M.D.B.; Oltra, C.; Desbarats, J.; Riesch, H.; Reiner, D. Communicating CCS: Applying communications theory to public perceptions of carbon capture and storage. Int. J. Greenh. Gas Control 2011, 5, 1651-1662. [CrossRef]

79. Brunsting, S.; de Best-Waldhober, M.; Brouwer, A.; Riesch, H.; Reiner, D. Communicating CCS: Effects of text-only and text-andvisual depictions of CO2 storage on risk perceptions and attitudes. Energy Procedia 2013, 37, 7318-7326. [CrossRef]

80. Dütschke, E. What drives local public acceptance-Comparing two cases from Germany. Energy Procedia 2011, 4, 6234-6240. [CrossRef]

81. Ter Mors, E.; Weenig, M.W.; Ellemers, N.; Daamen, D.D. Effective communication about complex environmental issues: Perceived quality of information about carbon dioxide capture and storage (CCS) depends on stakeholder collaboration. J. Environ. Psychol. 2010, 30, 347-357. [CrossRef]

82. D'Amore, F.; Lovisotto, L.; Bezzo, F. Introducing social acceptance into the design of CCS supply chains: A case study at a European level. J. Clean. Prod. 2020, 249, 119337. [CrossRef]

83. Von Rothkirch, J.; Ejderyan, O. Anticipating the Social Fit of CCS Projects by Looking at Place Factors. Int. J. Greenh. Gas Control 2021, 110, 103399. [CrossRef]

84. Boudet, H.S. Public perceptions of and responses to new energy technologies. Nat. Energy 2019, 4, 446-455. [CrossRef]

85. Pietzner, K.; Schumann, D.; Tvedt, S.D.; Torvatn, H.Y.; Næss, R.; Reiner, D.M.; Anghel, S.; Cismaru, D.; Constantin, C.; Daamen, D.D.; et al. Public awareness and perceptions of carbon dioxide capture and storage (CCS): Insights from surveys administered to representative samples in six European countries. Energy Procedia 2011, 4, 6300-6306. [CrossRef]

86. Braun, C. Not in my backyard: CCS sites and public perception of CCS. Risk Anal. 2017, 37, 2264-2275. [CrossRef]

87. Haug, J.K.; Stigson, P. Local Acceptance and communication as crucial elements for realizing CCS in the Nordic region. Energy Procedia 2016, 86, 315-323. [CrossRef]

88. Krause, R.M.; Carley, S.R.; Warren, D.C.; Rupp, J.A.; Graham, J.D. “Not in (or under) my backyard”: Geographic proximity and public acceptance of carbon capture and storage facilities. Risk Anal. 2014, 34, 529-540. [CrossRef]

89. Ter Mors, E.; Terwel, B.; Daamen, D.D. The potential of host community compensation in facility siting. Int. J. Greenh. Gas Control 2012, 11, S130-S138. [CrossRef]

90. Terwel, B.; ter Mors, E.; Daamen, D.D. It's not only about safety: Beliefs and attitudes of 811 local residents regarding a CCS project in Barendrecht. Int. J. Greenh. Gas Control 2012, 9, 41-51. [CrossRef] 
91. Terwel, B.W.; Koudenburg, F.A.; ter Mors, E. Public responses to community compensation: The importance of prior consultations with local residents. J. Community Appl. Soc. Psychol. 2014, 24, 479-490. [CrossRef]

92. Terwel, B.W.; ter Mors, E. Host community compensation in a carbon dioxide capture and storage (CCS) context: Comparing the preferences of Dutch citizens and local government authorities. Environ. Sci. Policy 2015, 50, 15-23. [CrossRef]

93. Warren, D.C.; Carley, S.R.; Krause, R.M.; Rupp, J.A.; Graham, J.D. Predictors of attitudes toward carbon capture and storage using data on world views and CCS-specific attitudes. Sci. Public Policy 2014, 41, 821-834. [CrossRef]

94. Zaal, M.P.; Terwel, B.W.; Ter Mors, E.; Daamen, D.D. Monetary compensation can increase public support for the siting of hazardous facilities. J. Environ. Psychol. 2014, 37, 21-30. [CrossRef]

95. Wolsink, M. Invalid theory impedes our understanding: A critique on the persistence of the language of NIMBY. Trans. Inst. Br. Geogr. 2006, 31, 85-91. [CrossRef]

96. Burningham, K. Using the language of NIMBY: A topic for research, not an activity for researchers. Local Environ. 2000, 5, 55-67. [CrossRef]

97. Anderson, C.; Schirmer, J.; Abjorensen, N. Exploring CCS community acceptance and public participation from a human and social capital perspective. Mitig. Adapt. Strat. Glob. Chang. 2012, 17, 687-706. [CrossRef]

98. Ashworth, P.; Bradbury, J.; Wade, S.; Feenstra, C.Y.; Greenberg, S.; Hund, G.; Mikunda, T. What's in store: Lessons from implementing CCS. Int. J. Greenh. Gas Control 2012, 9, 402-409. [CrossRef]

99. Bradbury, J. Public understanding of and engagement with CCS. In The Social Dynamics of Carbon Capture and Storage: Understanding CCS Representations, Governance and Innovation; Markusson, N., Shackley, S., Evar, B., Eds.; Routledge: New York NY, USA, 2012.

100. Bradbury, J.; Ray, I.; Peterson, T.; Wade, S.; Wong-Parodi, G.; Feldpausch, A. The role of social factors in shaping public perceptions of CCS: Results of multi-state focus group interviews in the U.S. Energy Procedia 2009, 1, 4665-4672. [CrossRef]

101. Sala, R.; Oltra, C. Experts' attitudes towards CCS technologies in Spain. Int. J. Greenh. Gas Control 2011, 5, 1339-1345. [CrossRef]

102. Thompson, M.; Ellis, R.; Wildavsky, A. Cultural Theory; Westview Press: Nashville, TN, USA, 1990; Volume XVI.

103. Minkov, M. Cross-Cultural Analysis: The Science and Art of Comparing the World's Modern Societies and Their Cultures; SAGE Publications: Melbourne, VIC, Australia, 2013.

104. Benedict, R. Patterns of Culture; Houghton Mifflin Harcourt: Boston, MA, USA, 1934.

105. Douglas, M. Cultural Bias; Royal Anthropological Institute: London, UK, 1987.

106. Geertz, C. The Interpretation of Cultures; Basic Books: New York, NY, USA, 1973.

107. Kluckhohn, C. The study of culture. In The Policy Sciences; Lerner, D., Lasswell, K., Eds.; Stanford University Press: Redwood City, CA, USA, 1951; pp. 86-101.

108. Kroeber, A.L.; Parsons, T. The concepts of culture and of social system. Am. Sociol. Rev. 1958, 23, 582-583.

109. White, L. The Evolution of Culture: The Development of Civilization to the Fall of Rome; McGraw-Hill: New York, NY, USA, 1959.

110. Berry, J.W. On Cross-Cultural Comparability. Int. J. Psychol. 1969, 4, 119-128. [CrossRef]

111. Child, J. Culture, contingency and capitalism in the cross-national study of organisations. Res. Organ. Behav. $1981,3,303-356$.

112. Hofstede, G. Cultural Consequences, 1st ed.; Sage: Thousand Oaks, CA, USA, 1980.

113. Jahoda, G. Do we need a concept of culture? J. Cross-Cult. Psychol. 1984, 15, 139-151. [CrossRef]

114. Poortinga, Y.H.; Van De Vijver, F.J.R. Explaining cross-cultural differences. J. Cross-Cult. Psychol. 1987, 18, 259-282. [CrossRef]

115. Hofstede, G. Culture's Consequences: Comparing Values, Behaviors, Institutions and Organizations across Nations, 2nd ed.; SAGE Publications Inc.: Melbourne, VIC, Australia, 2001.

116. Bond, M.H.; Leung, K.; Au, A.K.-C.; Tong, K.-K.; De Carrasquel, S.R.; Murakami, F.; Yamaguchi, S.; Bierbrauer, G.; Singelis, T.M.; Broer, M.; et al. Culture-level dimensions of social axioms and their correlates across 41 cultures. J. Cross-Cult. Psychol. 2004, 35, 548-570. [CrossRef]

117. Smith, P.B.; Dugan, S.; Trompenaars, F. National culture and the values of organizational employees. J. Cross-Cult. Psychol. 1996, 27, 231-264. [CrossRef]

118. Almond, G.A.; Verba, S. Political Culture: Political Attitudes and Democracy in Five Nations; Princeton University Press: Princeton, NJ, USA, 1963.

119. Leung, K.; Bond, M.H.; De Carrasquel, S.R.; Muñoz, C.; Hernández, M.; Murakami, F.; Yamaguchi, S.; Bierbrauer, G.; Singelis, T.M. Social axioms: The search for universal dimensions of general beliefs about how the world functions. J. Cross-Cult. Psychol. 2002, 33, 286-302. [CrossRef]

120. Beugelsdijk, S.; Maseland, R.; van Hoorn, A. Are scores on Hofstede's dimensions of national culture stable over time? A cohort analysis. Glob. Strat. J. 2015, 5, 223-240. [CrossRef]

121. Maleki, A. Patterns of Culture and Models of Democracy: Towards the Cultural Compatibility Thesis of Democracy. Ph.D. Thesis, Tilburg University, Tilburg, The Netherlands, June 2015. Available online: http:/ / www.narcis.nl/publication/RecordID/oai: tilburguniversity.edu:publications\%2F4a35568c-498f-45f7-a4ae-e268b9d44efb (accessed on 1 September 2021).

122. Triandis, H.C. The Analysis of Subjective Culture; Wiley-Interscience: Hoboken, NJ, USA, 1972; Volume XII.

123. Maleki, A.; De Jong, M. A proposal for clustering the dimensions of national culture. Cross-Cult. Res. 2014, 48, 107-143. [CrossRef]

124. Verweij, M.; Ney, S.; Thompson, M. World. In Clumsy Solutions for a Wicked World: How to Improve Global Governance; Verwij, M., Ed.; Palgrave Macmillan: New York, NY, USA, 2011.

125. Hofstede, G.; Hofstede, G.J.; Minkov, M. Cultures and Organizations: Software of the Mind, 3rd ed.; McGraw-Hill: New York, NY, USA, 2010. 
126. Karimi, F.; Goulas, A.; Barzmehri, M.M.; Anggana Putri, M. CCS potential in Norway-Exploring the role of flagship projects: The Mongstad and Kårstø case studies. Int. J. Sustain. Water Environ. Syst. 2012, 4, 23-34.

127. Kojo, M.; Innola, E. Carbon capture and storage in the finnish print media. Risk Hazards Crisis Public Policy 2017, 8, 113-146. [CrossRef]

128. Pihkola, H.; Tsupari, E.; Kojo, M.; Kujanpää, L.; Nissilä, M.; Sokka, L.; Behm, K. Integrated sustainability assessment of CCS-Identifying non-technical barriers and drivers for CCS implementation in Finland. Energy Procedia 2017, 114, 7625-7637. [CrossRef]

129. Rodriguez, E.; Lefvert, A.; Fridahl, M.; Grönkvist, S.; Haikola, S.; Hansson, A. Tensions in the energy transition: Swedish and Finnish company perspectives on bioenergy with carbon capture and storage. J. Clean. Prod. 2021, 280, 124527. [CrossRef]

130. Pietzner, K.; Schwarz, A.; Duetschke, E.; Schumann, D. Media coverage of four carbon capture and storage (CCS) projects in Germany: Analysis of 1,115 regional newspaper articles. Energy Procedia 2014, 63, 7141-7148. [CrossRef]

131. Yle. Finns Trust Traditional Outlets More Than Social Media for Coronavirus News. Yle, 1 June 2020. Available online: https://yle. fi/uutiset/osasto/news/finns_trust_traditional_outlets_more_than_social_media_for_coronavirus_news/11378963(accessed on 1 September 2021). 